Article

\title{
Exploring the Non-Use Value of Important Agricultural Heritage System: Case of Lingnan Litchi Cultivation System (Zengcheng) in Guangdong, China
}

\author{
Fei Zhao ${ }^{1,2, *(\mathbb{D}) \text { and Min Huang }}{ }^{1}$ \\ 1 Institute of Chinese Agricultural Heritage, South China Agricultural University, Guangzhou 510642, China; \\ minhuang@stu.scau.edu.cn \\ 2 Department of Geography and Environment Management, University of Waterloo, \\ Waterloo, ON N2L 3G1, Canada \\ * Correspondence: zhaofei@scau.edu.cn; Tel./Fax: +86-20-85280251
}

Received: 26 March 2020; Accepted: 28 April 2020; Published: 1 May 2020

check for updates

\begin{abstract}
For the past decade, Important Agricultural Heritage Systems (IAHSs) have become research hotspots because of their rapidly increasing number. The non-use value is an important part of the value of an IAHS, and if ignored, the total value of an IAHS may be underestimated in part. Litchi is native to southern China, and its farming system is an important agricultural heritage with Chinese characteristics and global influence. In this context, the present study attempts to investigate the willingness to pay (WTP) of local residents and assess the non-use value of the Lingnan Litchi Cultivation System (Zengcheng) in Guangdong, China. To this aim, a survey was implemented on four sites in Zengcheng with the application of the contingent valuation method (CVM). Based on the analysis of 458 questionnaires, the WTP rate of residents in the heritage site is $66.6 \%$, and the mean WTP is 62.5 Chinese yuan (CNY) per year. The total non-use value of the Lingnan Litchi Cultivation System (Zengcheng) is 49.9 million CNY. The option, bequest, and existence values in 2018 are estimated to be 20.1,13.7, and 16.1 million CNY, respectively. Results of the logistic regression analysis indicate that variables of age, education level, financial burden, and heritage value cognition are significant factors of WTP for protecting litchi heritage. Compared with similar studies in China, the mean WTP and positive payment rate in this study are at a medium level. Resource attributes and local cultures may have significant impacts on the composition and estimate of the non-use value of an IAHS. The results of this study can be beneficial to the dynamic conservation and adaptive management of IAHSs.
\end{abstract}

Keywords: ancient tree; China-Nationally Important Agricultural Heritage System (China-NIAHS); Globally Important Agricultural Heritage Systems (GIAHS); Lingnan Litchi Cultivation System (Zengcheng); non-use value; willingness to pay

\section{Introduction}

\subsection{Important Agricultural Heritage System and Its Values}

Over the last three decades, agricultural heritage values have been increasingly recognized internationally [1]. Since the designation of Globally Important Agricultural Heritage Systems (GIAHS) in 2002 by the Food and Agriculture Organization of the United Nations (FAO), the dynamic conservation and adaptive management of agricultural heritage have become critical issues. According to the definition proposed by the FAO, the Important Agricultural Heritage System (IAHS) is a kind of complex agroecosystem maintained by a traditional society through a value system that has strong sociocultural interconnections with the local landscape [2]. Due to specific natural conditions 
and human activities, these agroecosystems always have production, ecological, cultural, and other functions, which lead to the multi-values of IAHSs. In recent years, global and regional socioeconomic changes (e.g., urbanization, modern agriculture, and industrialization) have resulted in a vulnerable situation for traditional agricultural systems and landscapes [3,4]. Therefore, the multi-values need to be fully recognized by policymakers before the policy support and actions are drafted and performed to promote the multifunctionality and sustainability of IAHSs $[5,6]$.

Similar to other types of heritages, IAHSs have two kinds of values: use and non-use values. The former refers to the value that can provide products or meet human needs, whereas the latter refers to the value that cannot be directly used at present but can be maintained for future generations. Non-use value is commonly defined as encompassing existence, bequest, and option values, and the connotation of the last one is between use and non-use values [7]. A sustainable mechanism within IAHSs is doomed to the diversity of value. For the past decade, the issue of IAHS conservation has become a concern due to their rapidly increasing number. Many studies explore the use values of IAHSs. These studies prove that IAHSs can bring multiple benefits to heritage sites, such as cultural identity, food security, the conservation of natural resources, poverty alleviation, agrobiodiversity utilization and conservation, a source of valuable agricultural knowledge, and cultural diversity [8]. After regarding traditional agricultural systems as cultural heritage, the economic benefits grow greatly [9]. At the present stage, the multifunctional agriculture based on IAHSs' values is the main pathway for economic development in IAHS sites, including the production of high-quality and local agricultural products, the expansion of ecotourism, and the advancement of cultural industries [10,11]. As a public good, IAHSs have no means for direct market transactions. The non-use value of IAHSs cannot be measured by the market price method, leading to easy negligence and, thus, distorting value evaluation [12]. The cores of IAHSs are the function of traditional production systems and the mechanism of sustainable development [13]. Compared with other types of heritage, the dynamic characteristic of agricultural heritage is more prominent. Farmers are viewed as major caretakers in IAHS sites, and agricultural production plays an important role in the social and economic system that is constantly changing over time [14,15]. In certain heritage sites, authorities and residents always take the well-known heritage as a tool to obtain economic benefit. Exploring the sustainable mechanism of heritage systems is extremely urgent given that various traditional agricultural production systems are disappearing rapidly [16]. Studying the non-use value of IAHSs is necessary and bears great significance for heritage conservation and adaptive management.

\subsection{Literature Review}

The earliest study on the composition of non-use value can be traced back to the 1960s. During this period, a rapid development stage of the environmental protection movement in the US was evident. John V. Krutilla, known as the founder of environmental economics, put forward the concept of non-use value in 1967. He believed that people could obtain satisfaction from knowing about the existence of natural resources; this knowledge is enough to justify their willingness to pay (WTP) for such resources [17]. Later, the viewpoint that non-use value consists of option, bequest, and existence values was widely recognized by Carson, Pearce, and other scholars. Carson believed that the three parts are independent of each other and can be calculated separately $[18,19]$. The assessment and influencing factors of non-use value has been an important field of research on the economic value of natural resources since the 1990s. According to statistics from 2017, more than 300 studies have been conducted to explore the non-use value of tourism resources [20,21].

IAHSs, including natural and cultural resources, refer to farming systems with heritage values which contain non-use value [11]. Although the non-use value of IAHSs does not leave a trace in market behavior, such a value mainly arises from the pure pleasure of knowing that certain heritages exist. The people concerned often never directly or indirectly benefit from the system but still want to preserve it to satisfy the idea of existence [22]. Previous studies on the non-use value of IAHS sites are mainly conducted from the aspects of WTP and non-use value evaluation. Nowadays, China 
has a leading position in IAHS studies around the world, and Chinese scholars have contributed the most to non-use value research. The case study of a GIAHS site in southeast China (Fuzhou Jasmine Planted and Tea Cultural Systems) finds that income level and donor history play important roles in farmers' decisions on whether to pay and how much to pay. Income level, donor history, and education level play key roles in urban residents' payment decisions. Meanwhile, the amounts and ratio of farmers' WTP are significantly lower than that of urban residents [23]. Generally, heritage resources are characterized by intensive distribution in an IAHS's core area, and most residents here tend to join the team for protecting the heritage. In the Chongyi Hakka Terraced System, which is a GIAHS site in east China, the WTP of people in the core area is slightly higher than that of people in the non-core area, indicating that the level of enthusiasm for an IAHS mainly affects the WTP. Core-area residents' financial burden and consciousness of the living environment have greater effects on their WTP, while non-core-area residents' income and education levels have a significant influence on their WTP and both are positively correlated [12]. Previous studies have found heterogeneous results regarding the relationship between the WTP and the distance to the good or service being valued. Contrary to expectations, the results of a case study on the GIAHS site the Archipelago of Chiloé in Chile show no significant differences in the WTP for the IAHS conservation when respondents are segmented by distance [24]. In sum, the exploration of the non-use value of IAHSs remains in its infancy, and the studied cases are limited. The morphological attributes and property rights arrangements of resources have significant impacts on the composition ratio of non-use value; thus, the impact of differences in resource attributes should be considered sufficiently [25-27]. In addition, IAHSs have numerous types, such as landscape, technology, and relic-based types. The non-use value characteristics of different heritages may not follow the same rules. Obviously, additional case and comparative studies need to be performed in this field [28].

Litchi (Litchi chinensis Sonn), which has a history of more than 2300 years of cultivation, is native to the Lingnan area in China. In a literal sense the word "Lingnan" means "south of the mountain range", a term referring to the area covering Guangdong, Guangxi, Hainan, Hong Kong, and Macao. Although praised as the "King of Fruits" by Chinese people, it can only grow luxuriantly in a few of the southern provinces (e.g., Guangdong, Guangxi, Fujian, and Hainan) in ancient China. Since the Tang Dynasty (608-907), Chinese people have always had a zealous enthusiasm for litchi, and writers have left countless historical records and literary works about it, mainly because of its status of the royal tribute and the extreme difficulty in retaining its freshness. The foreign introduction of Chinese-cultivated litchi began at the end of the 17th century. Nearly 100 years later, litchi had been planted in Burma, India, Nepal, Bengal, and Thailand [29]. By the second half of the 19th century, Europeans and overseas immigrants from southern China had successfully introduced litchi to Australia, the US, and a few European colonies [30,31]. In sum, the litchi farming system is an important agricultural heritage with Chinese characteristics and global influence. Exploring the non-use value of litchi heritage systems can fill the gap of relevant case studies to an extent.

\section{Research Objects and Methods}

\subsection{Lingnan Litchi Cultivation System (Zengcheng)}

Litchi is a typical subtropical fruit tree, which is mainly planted in two long and narrow climatic zones with latitudes of $17^{\circ}$ to $23^{\circ}$ in the South and North, respectively. At present, litchi is planted in approximately 32 countries around the world, with a total area of approximately 750,000 hm${ }^{2}$ [32]. In the early 1920s, horticulturist George W. Groff, who was the first agricultural missionary to China, and botanist and agronomist Wilson Popenoe said that the surrounding area of Guangzhou City was the ideal, and even the most suitable area, for litchi cultivation [30,33]. The Lingnan Litchi Cultivation System (Zengcheng) (Figure 1), a China-Nationally Important Agricultural Heritage System (China-NIAHS) site, is located in Zengcheng District, Guangzhou City, Guangdong Province. Zengcheng, located at $113^{\circ} 32^{\prime} \sim 114^{\circ} 0^{\prime} \mathrm{E}$ and $23^{\circ} 05^{\prime} \sim 23^{\circ} 37^{\prime} \mathrm{N}$, covers an area of $1616.47 \mathrm{~km}^{2}$ and has 
a subtropical marine monsoon climate, with the Tropic of Cancer running through its northern part. This region's terrain is high in the north and low in the south, whereas the central and northern parts are dominated by low mountains. The low hills and platforms are concentrated in the central and southern parts. The southern part is the alluvial plain of the Pearl River Delta. The main rivers in Zengcheng are the Dong, Zeng, and Xifu Rivers.

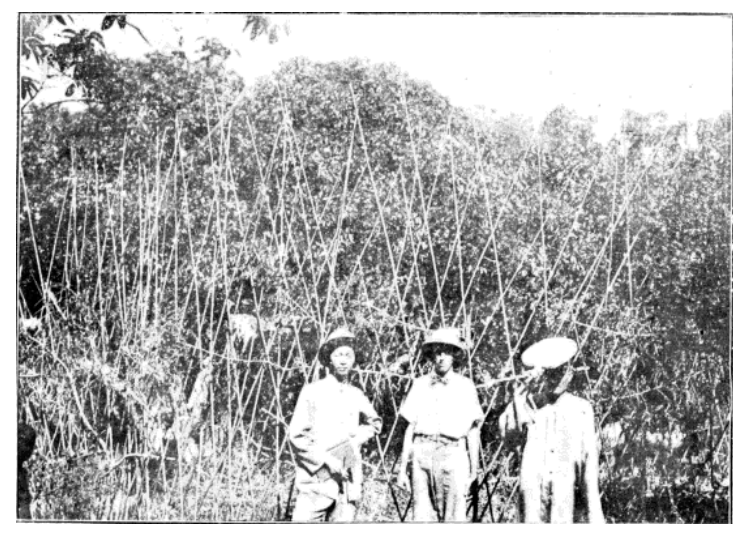

(a)

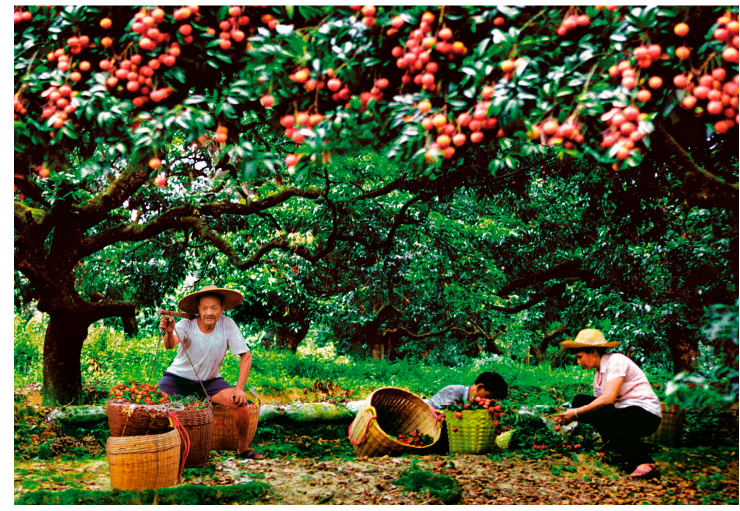

(c)

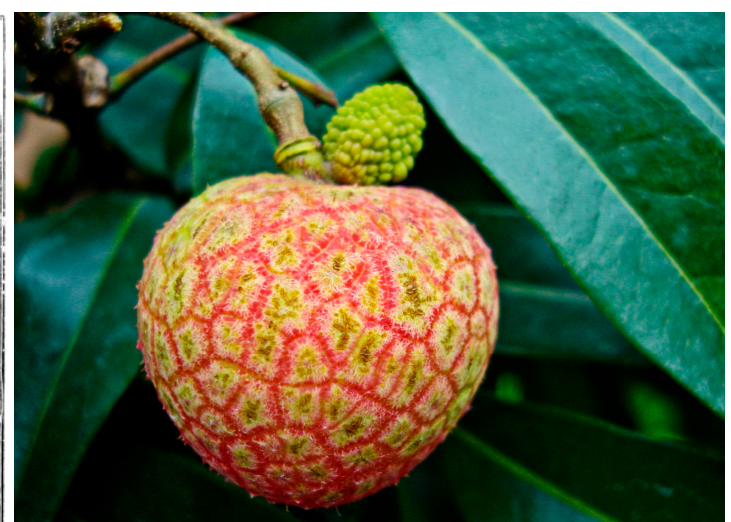

(b)

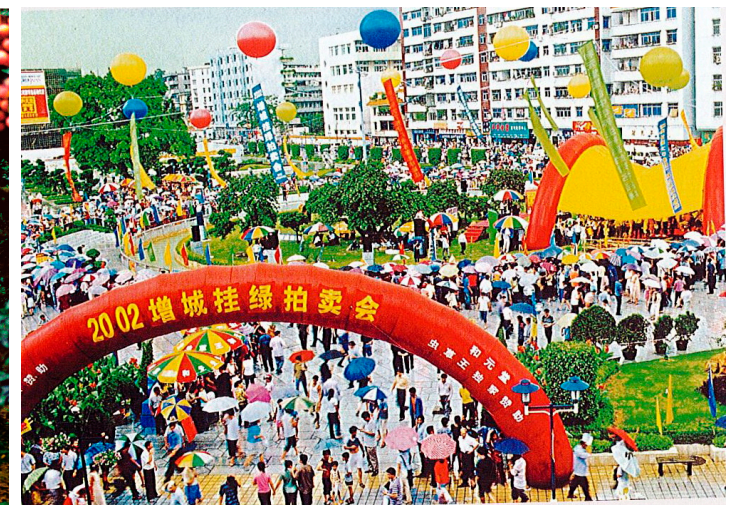

(d)

Figure 1. Photos of the Lingnan Litchi Cultivation System (Zengcheng). (a) George W. Groff (Middle) and the only mother tree of "Gualü" litchi in Zengcheng on June 28, 1918; (b) fruit of the only mother tree of "Gualü" litchi (Credit: Meijing Liao); (c) ancient litchi trees in the harvest season (Credit: Yunying Ye);

(d) Zengcheng Litchi Festival in 2002 (Credit: Zengcheng District Archives).

The superior natural environment and a long history of litchi cultivation have co-created the rich heritage of the Zengcheng Litchi. Zengcheng has a long history of cultivated litchi with a great reputation. Roughly 1600 years ago, a book, Guangzhou Notes, recorded that two nearly 20-m-high litchi trees exist in the north of Zengcheng. Only between the 11th and 20th centuries, more than 90 poems on the Zengcheng Litchi were written by notable poets or politicians. "Gualü" litchi, one of the most valuable cultivars, is native to Zengcheng, where its fruit can keep the peculiar shape and flavor. After a long-term misfortune, only one mother tree of the "Gualü" litchi survived at the end of Qing Dynasty (1636-1912). In the past 1000 years, Zengcheng had been famous for its abundance of litchi cultivars. The Zengcheng Litchi Manual, written by Zongmin Zhang in 1076, records that more than 100 cultivars existed. Nowadays, litchi trees of 71 cultivars flourish in Zengcheng. More than 15,000 centuries-old ancient trees are scattered throughout the whole region. Zengcheng's litchi culture is rich and diverse in form. A total of 126 places have names with the word “荔” (Litchi). The tradition of holding litchi festivals and inviting relatives and friends to drink litchi wine continues to this day. The folk story named Female Celestial He (He Xiangu) and "Gualü" Litchi and the traditional craftsmanship of litchi furniture are included in the list of intangible cultural heritages. 
For a long time, the litchi industry development and cultivation technology in Zengcheng have been in a leading position. In the early 1990s, litchi was planted in 286 villages of less than 300 villages in Zengcheng [34]. In 2012, the "Zengcheng Gualü Litchi" and the "Zengcheng Litchi" were approved as Chinese Protected Geographical Indication Products. In recent years, the planting area of litchi has been stable at approximately $11,500 \mathrm{hm}^{2}$. In sum, the Lingnan Litchi Cultivation System (Zengcheng) is an agricultural production and cultural system with strong value in ecology, economy, and culture. However, its sustainability is currently faced with threats posed by urban expansion, scaled agricultural development, and weak protection for ancient litchi trees [35].

\subsection{Research Method}

The contingent valuation method (CVM) is the most widely used for assessing the non-use value of natural resources in the fields of ecology and environmental economics because of its applicability, flexibility, and the strong ability of the data sources. Since 2000, the CVM has been increasingly applied to cultural heritages, such as historic sites, museums, archeological sites, and cultural goods [36,37]. As a new type of heritage, agricultural heritage is an agriculture production system which is a coexistence of natural and cultural resources. Hence, using the CVM to measure the non-use value of IAHSs is feasible. The CVM is used to put forward a hypothetical market to the public first and then estimate the economic value of the appraised object by means of a questionnaire survey and interviews with regard to people's willingness to pay for or accept the resource protection or improvement measures of a certain environmental benefit $[21,38]$. The present study drew on the experience of other studies to make corresponding countermeasures for the possible biases of the CVM. SPSS 22.0 was used for the statistical analysis of data in this study.

In terms of the questionnaire issuance, although the nature of the respondents was initially selected, most of them were random samples to ensure certain uncertainty. To ensure the representativeness of the respondent samples, a reasonable sample number or size should be determined. In this study, the sample size was defined by Scheaffer's sampling formula:

$$
N=\frac{n}{(n-1) \delta^{2}}+1
$$

where $N$ is the entire sample population, $n$ is the number of the Zengcheng resident population, and $\delta$ is the sampling error $(\delta=5 \%)$. According to the Statistical Bulletin of Zengcheng Economic and Social Development (2017), the number of Zengcheng's population had reached 119.83 million. After calculating the sample size on the basis of the sampling consensus, at least 401 valid samples were needed for the non-use value assessment of the Lingnan Litchi Cultivation System (Zengcheng).

Based on the 15 investigative principles cited by a report of the US National Oceanic and Atmospheric Administration, the CVM was used to design the questionnaire [36]. Drawing on the characteristics of Zengcheng's litchi heritage and previous studies, the questionnaire was mainly divided into three parts:

(1) Introduction of Zengcheng's litchi heritage. The investigators first briefly explained the purpose of the interview. Then, an introduction, with pictures of the China-NIAHS and Zengcheng's litchi heritage, was provided for the respondents to give them a clear picture of this study.

(2) Residents' perception of Zengcheng's litchi heritage. This part contained questions concerning the respondents' profiles, such as their gender, age, education level, occupation, monthly income, and financial burden status. Questions were also asked to identify the degree of participants' awareness of the protection and non-use value of Zengcheng's litchi heritage. To protect the privacy of the respondents and avoid conflicting feelings, the interviewees were investigated anonymously.

(3) Residents' WTP to protect Zengcheng's litchi heritage. The third part was the survey of WTP for protecting heritage, which is the core of non-use value evaluation. First, a hypothetical market was constructed in the questionnaire by asking the residents about their WTP to protect the litchi heritage. The investigators then reminded the residents to answer the questions according to their 
own real-life situations to improve the authenticity of their WTP. The scope of the WTP for the bidding values in the questionnaire was determined to be $1,5,10,15,20,30,50,80,100,200,300,500$, and $>500$ (Chinese Yuan, CNY).

The first draft of questionnaires was completed in mid-September 2018. The questionnaires were initially administered face-to-face to conduct a preliminary survey by the end of September, wherein 50 questionnaires were completed in Zhongxin Town. According to the feedback of the pre-survey, the questionnaire was further revised. From mid-October to mid-December 2018, the formal investigation was initiated in Zhongxin, Gualü Plaza, Liantang Village, and Qiaotou Village (Figure 2). Overall, 458 of the 480 returned questionnaires were valid, with an effective rate of $95.4 \%$. Among them, 151 and 94 questionnaires were completed in the Gualü Plaza and Zhongxin in mid-October, and 50 and 163 questionnaires were completed in Liantang Village and Qiaotou Village in mid-December 2018, respectively.

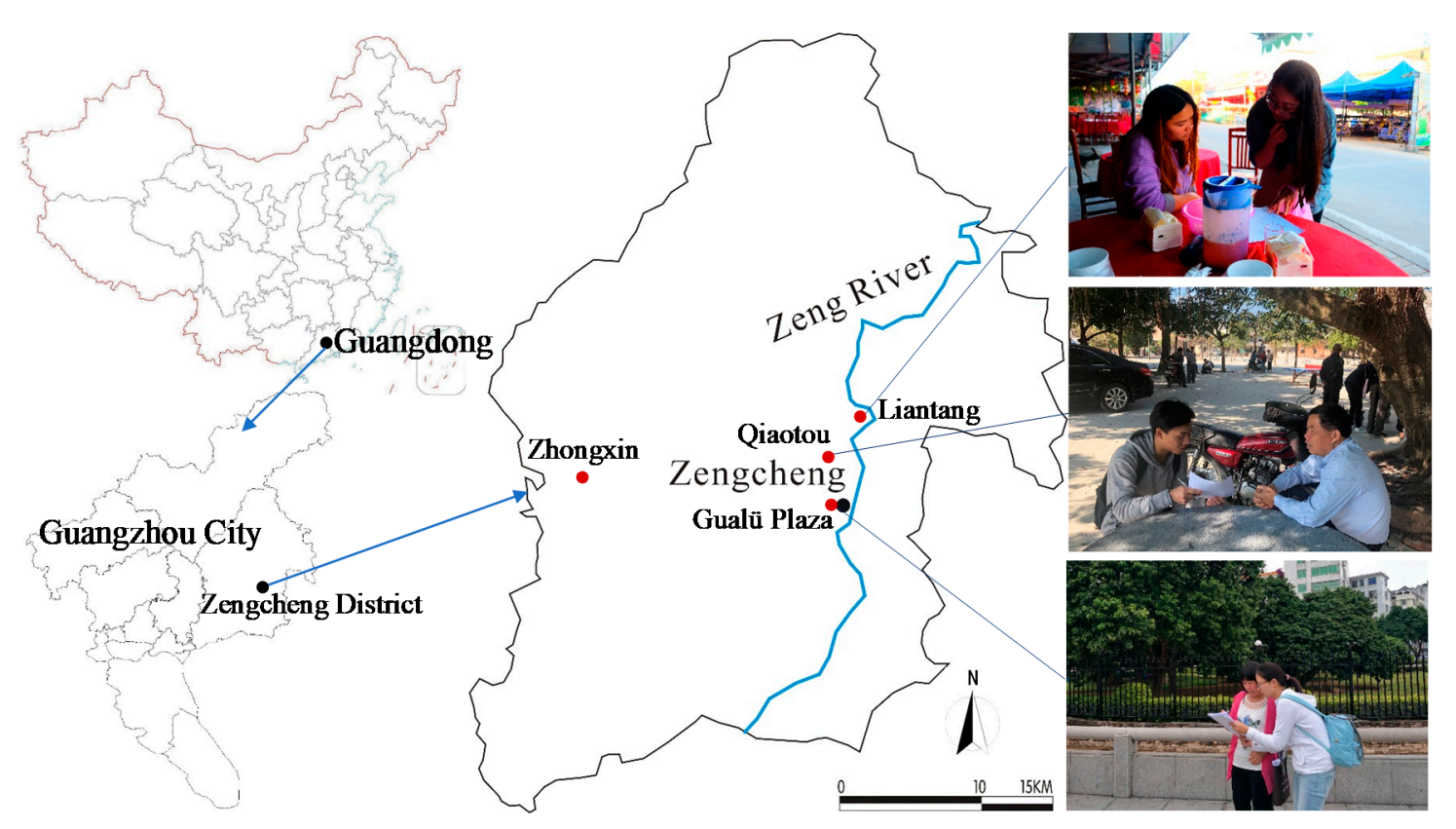

Figure 2. Location of investigation sites.

\section{Results}

\subsection{Respondents' Demographic Characteristics}

Table 1 shows the distribution of demographic characteristics of 458 respondents. The number of female respondents $(51.3 \%)$ exceeded that of male respondents $(48.7 \%)$, and the age of most respondents $(66.1 \%)$ ranged from 20 to 40 years old. Most respondents were not highly educated, with respondents whose education level was concentrated in primary and middle school education accounting for $74.0 \%$ of the sample. Farmers composed $40 \%$ of the respondents, and the remaining occupational distribution was diverse, including self-employed $(16.2 \%)$, company employee $(10.9 \%)$, staff of government and public institutions $(9.6 \%)$, students $(8.1 \%)$, and others $(15.3 \%)$. The monthly income of the respondents was mostly concentrated between less than 2000 CNY and 2001-4000 CNY, accounting for $69.4 \%$, and $15.9 \%$ of respondents earned more than $6000 \mathrm{CNY}$. A direct inverse relationship was observed between income level and financial burden. According to the data, only $17.6 \%$ of respondents felt less perceptive of financial burden, whereas the remaining $82.4 \%$ had a more obvious perception of financial pressure. 
Table 1. Respondents' profiles.

\begin{tabular}{|c|c|c|c|c|c|}
\hline Item & Sub-Item & Frequency (\%) & Item & Sub-Item & Frequency (\%) \\
\hline \multirow{3}{*}{ Gender } & Male & $223(48.7)$ & \multirow{5}{*}{ Education level } & Primary school & 80 (17.5) \\
\hline & Female & $235(51.3)$ & & Junior middle school & $143(31.2)$ \\
\hline & $20-30$ & $155(33.8)$ & & Senior middle school & $116(25.3)$ \\
\hline \multirow{3}{*}{ Age } & $31-40$ & $248(32.3)$ & & College degree and above & $119(26.0)$ \\
\hline & $41-50$ & $79(17.2)$ & & $<2000 \mathrm{CNY}$ & $153(33.4)$ \\
\hline & $51-60$ & $44(9.6)$ & \multirow{2}{*}{$\begin{array}{l}\text { Monthly } \\
\text { income }\end{array}$} & 2001-4000 CNY & $165(36.0)$ \\
\hline \multirow{7}{*}{ Job } & $>60$ & $42(9.2)$ & & 4001-6000 CNY & $67(14.6)$ \\
\hline & Farmer & $183(40.0)$ & \multirow{6}{*}{$\begin{array}{l}\text { Financial } \\
\text { burden }\end{array}$} & $>6000 \mathrm{CNY}$ & $73(15.9)$ \\
\hline & Self-employed & $74(16.2)$ & & No & $35(7.6)$ \\
\hline & Company employee & $50(10.9)$ & & A little & $46(10.0)$ \\
\hline & $\begin{array}{l}\text { Staff of government } \\
\text { and public institutions }\end{array}$ & $44(9.6)$ & & Medium & $229(50.0)$ \\
\hline & Student & $37(8.1)$ & & Heavy & $116(25.3)$ \\
\hline & Others & $70(15.3)$ & & Serious & $32(7.0)$ \\
\hline
\end{tabular}

\subsection{Residents' WTP Estimation}

A total of 305 respondents expressed their willingness to pay a certain fee for protecting the litchi heritage, which accounted for $66.6 \%$. In this study, we set the residents' possible payments from 1 to $500 \mathrm{CNY}$ or more. The highest frequency was $100 \mathrm{CNY}$ per year, accounting for $19.0 \%$. The WTP 100 CNY or less per year also contributed the largest cumulative amount (71\%) to the total WTP. Evidently, most respondents tended to choose a small payment amount within the scope of their financial capability. The respondents' possible payments amounted from 1 to 1000 CNY. SPSS was used to determine the statistical frequency (Table 2). The median value, which is the one with the cumulative frequency of $50 \%$, is usually used to represent the mean WTP of a public good to guarantee the reliability and fairness of the WTP [39]. According to Table 2, the cumulative frequency closest to $50 \%$ was $48.5 \%$ and $52.1 \%$, and the corresponding payment value ranged between 50 and $80 \mathrm{CNY}$ per year. Using the linear interpolation method, the median WTP corresponding to the cumulative frequency of $50 \%$ was $62.5 \mathrm{CNY}$ per year.

Table 2. Frequency of respondents' WTP.

\begin{tabular}{cccccc}
\hline & $\begin{array}{c}\text { WTP } \\
(\mathbf{C N Y})\end{array}$ & Frequency & $\begin{array}{c}\text { Percentage } \\
\mathbf{( \% )}\end{array}$ & $\begin{array}{c}\text { Effective } \\
\text { Percentage (\%) }\end{array}$ & $\begin{array}{c}\text { Cumulative } \\
\text { Percentage (\%) }\end{array}$ \\
\hline 1.00 & 5 & 1.1 & 1.6 & 1.6 \\
& 5.00 & 10 & 2.2 & 3.3 & 4.9 \\
10.00 & 16 & 3.5 & 5.2 & 10.2 \\
& 15.00 & 17 & 3.7 & 5.6 & 15.7 \\
& 20.00 & 27 & 5.9 & 8.9 & 24.6 \\
& 30.00 & 35 & 7.6 & 11.5 & 36.1 \\
& 50.00 & 38 & 8.3 & 12.5 & 48.5 \\
& 80.00 & 11 & 2.4 & 3.6 & 52.1 \\
& 100.00 & 58 & 12.7 & 19.0 & 71.1 \\
& 200.00 & 36 & 7.9 & 11.8 & 93.0 \\
& 300.00 & 25 & 5.5 & 8.2 & 98.4 \\
& 500.00 & 22 & 4.8 & 7.2 & 99.0 \\
& 600.00 & 2 & 0.4 & 0.7 & 100.0 \\
& 800.00 & 2 & 0.4 & 0.7 & \\
\hline & 1000.00 & 1 & 0.2 & 0.3 & \\
\hline
\end{tabular}




\subsection{Factors Affecting Residents' WTP}

Based on referring to previous studies, a logistic regression model was applied to isolate significant factors influencing the respondents' answers to the alternative WTP elicitation questions on protecting Zengcheng's litchi heritage $[12,21,40]$. The following aspects were selected as the dependent variables: gender, age, job, education level, monthly income, financial burden, evaluation of heritage value, and heritage protection cognition. These variables were assigned as shown in Table 3 . This study also set 13 options for the payment amount setting, wherein the statistical results of WTP were reclassified to account for the needs to simplify the model. After classification, the model was adjusted as follows: $\mathrm{Y}=0, \mathrm{WTP}=0 ; \mathrm{Y}=1, \mathrm{WTP}=[1-50) ; \mathrm{Y}=2, \mathrm{WTP}=[50-200) ; \mathrm{Y}=3, \mathrm{WTP}=[200-500] ; \mathrm{Y}=4, \mathrm{WTP}>500$. According to the amount distribution, these five categories represented respondents' protest, low, medium, high, and unexpected payments.

Table 3. Variables for the logistic regression model and their transformation.

\begin{tabular}{|c|c|}
\hline Variable (Identifier) & Mutator \\
\hline Gender & "Male" = 1; "Female" = 2 \\
\hline Age & 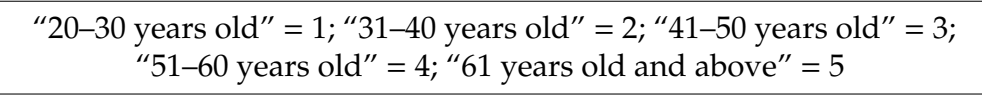 \\
\hline Education level & $\begin{array}{c}\text { "Primary school" = } 1 ; \text { " Junior middle school" = 2; "Senior middle } \\
\text { school" = } 3 ; \text { "College degree and above" }=4\end{array}$ \\
\hline Job & $\begin{array}{l}\text { "Student" }=1 \text {; "Farmer" = 2; “Others" = 3; "Company employee" }=4 ; \\
\text { "Staff of government and public institution" = 5; "Self-employed" = } 6\end{array}$ \\
\hline Monthly income & 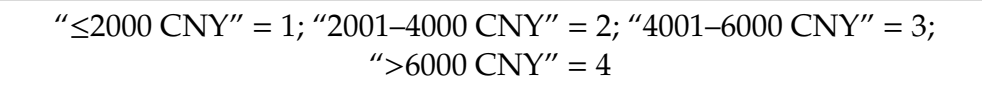 \\
\hline Financial burden & "No" = 1; "A little" = 2; "Medium" = 3; "Heavy" = 4; "Serious" = 5 \\
\hline Heritage value cognition & $\begin{array}{c}\text { "Worthless" = } 1 ; \text { “Small significance" = 2; “Common" = 3; } \\
\text { "Precious" = 4; "Very precious" = 5 }\end{array}$ \\
\hline Heritage protection evaluation & "Very bad" = 1; "Bad" = 2; "Common" = 3; “Good" = 4 \\
\hline
\end{tabular}

The results of the logistic regression model test (Table 4) showed that four variables, namely, age, education level, financial burden, and heritage value cognition had significant impacts on the WTP, whereas four variables, namely gender, job, income, and heritage protection evaluation exerted little effect on the WTP of Zengcheng's residents. Family financial burden had a strong negative correlation with the WTP that was significant at the test level of 0.001, indicating that the greater the financial burden of Zengcheng's residents, the smaller the WTP. The regression coefficient of heritage value cognition was positive at the test level of 0.05 , suggesting that the higher the recognition of the degree of heritage value, the clearer the recognition of the significance and necessity for protecting the litchi heritage and the more willing the residents were to paying a larger amount. Education level was also significant at the level of 0.05 , and the regression coefficient was positive, indicating that the higher the education level, the greater the WTP. Age had a significantly negative effect on the WTP at the test level of 0.05 , which showed that the increase of a resident's age brought about a decrease in the WTP. 
Table 4. Test results of the logistic regression model.

\begin{tabular}{|c|c|c|c|c|c|c|}
\hline & \multirow[b]{2}{*}{ Estimate } & \multirow{2}{*}{$\begin{array}{l}\text { Standard } \\
\text { Error }\end{array}$} & \multirow[b]{2}{*}{ Wald } & \multirow{2}{*}{$\begin{array}{c}\text { Significance } \\
\text { Level }\end{array}$} & \multicolumn{2}{|c|}{ 95\% Confidence Interval } \\
\hline & & & & & $\begin{array}{l}\text { Lower } \\
\text { Bound }\end{array}$ & $\begin{array}{l}\text { Upper } \\
\text { Bound }\end{array}$ \\
\hline$[\mathrm{Y}=0]$ & -0.863 & 0.866 & 0.994 & 0.319 & -2.560 & 0.834 \\
\hline$[\mathrm{Y}=1]$ & 0.206 & 0.865 & 0.057 & 0.812 & -1.489 & 1.902 \\
\hline$[\mathrm{Y}=2]$ & 1.439 & 0.867 & 2.754 & 0.097 & -0.261 & 3.140 \\
\hline$[\mathrm{Y}=3]$ & $4.642 * * *$ & 0.971 & 22.863 & 0.000 & 2.739 & 6.544 \\
\hline Gender & 0.233 & 0.178 & 1.718 & 0.190 & -0.115 & 0.582 \\
\hline Age & $-0.194 *$ & 0.079 & 6.090 & 0.014 & -0.348 & -0.040 \\
\hline Education level & $0.239 *$ & 0.108 & 4.943 & 0.026 & 0.028 & 0.450 \\
\hline Job & 0.024 & 0.067 & 0.128 & 0.720 & -0.107 & 0.154 \\
\hline Monthly income & -0.135 & 0.113 & 1.420 & 0.233 & -0.357 & 0.087 \\
\hline Financial burden & $-0.436^{* * *}$ & 0.094 & 21.763 & 0.000 & -0.619 & -0.253 \\
\hline Heritage value evaluation & $0.270 *$ & 0.123 & 4.843 & 0.028 & 0.030 & 0.510 \\
\hline Heritage protection evaluation & -0.055 & 0.139 & 0.155 & 0.694 & -0.327 & 0.218 \\
\hline
\end{tabular}

Note: The "** and "****" indicate the significance under $5 \%$ and $0.1 \%$ levels, respectively.

\subsection{Payment and Non-Payment Motivation}

Among all of the surveyed residents, 408 claimed that they have a full understanding of litchi heritage and support its protection, corresponding to a rate of $89.1 \%$. In this survey, the residents were asked about their willingness to participate in heritage protection. Most participants responded with "very willing" (22.8\%) and "willing, but no time" (68.4\%). In this study, 153 respondents chose the non-payment option, accounting for $33.4 \%$. For those residents, low economic income or heavy financial burden was the main reason for protesting payment, accounting for $40.4 \%$. Some respondents (29.5\%) regarded heritage protection as a government responsibility, and they believed that the protection fund should exclude personal donations. Of them, $12.8 \%$ refused to pay because they were unconvinced that the heritage management agencies would use the fund exclusively. A small group of people chose the items "heritage protection has nothing to do with $\mathrm{me}^{\text {" }}(11.5 \%)$ and "the exhaustion of cultural heritage is inevitable for social development" (5.8\%). During the interview, the investigators collected the respondents' viewpoints on Zengcheng's litchi heritage conservation. Although these opinions (Table 5) are somewhat subjective, they can provide a good supplement for the data statistics of residents' positive and negative responses.

Table 5. Respondents' perspectives on payment and non-payment motivation.

\begin{tabular}{|c|c|}
\hline $\begin{array}{l}\text { Respondent/ } \\
\text { Motivation }\end{array}$ & Representative Point of View \\
\hline A1 & $\begin{array}{c}\text { "Although we do not earn much money from ancient litchi trees, we cannot refuse to } \\
\text { protect them given that these trees are precious treasures left by our ancestors. Even little } \\
\text { boys know that in our village." }\end{array}$ \\
\hline $\mathrm{A} 2$ & $\begin{array}{l}\text { "Litchi is a synonym for Zengcheng District. In any case, we cannot let future generations } \\
\text { forget that. Books on Zengcheng's litchi culture should be provided for students to study." }\end{array}$ \\
\hline A3 & $\begin{array}{c}\text { "Due to alternate bearing, we cannot always obtain a stable income from litchi planting. } \\
\text { I hope to earn more money from the brand promotion of Zengcheng's litchi." }\end{array}$ \\
\hline A4 & $\begin{array}{l}\text { "My garden has a 'Gualü' litchi tree. I won a prize in the Zengcheng Litchi Festival last } \\
\text { year because of the delicious taste of the tree fruits. I will no doubt contribute to the } \\
\text { protection fund." }\end{array}$ \\
\hline B1 & $\begin{array}{l}\text { "I want to join the protection team for litchi heritage without pay. I think the government } \\
\text { must provide the fund, not the civilians." }\end{array}$ \\
\hline B2 & $\begin{array}{l}\text { "All things in the world will inevitably face death, and so will litchi trees. For example, } \\
\text { almost all sweet orange trees are dead because of yellow shoot disease in Zengcheng, } \\
\text { but what can we do?" }\end{array}$ \\
\hline
\end{tabular}


Table 5. Cont.

\begin{tabular}{cc}
$\begin{array}{c}\text { Respondent/ } \\
\text { Motivation }\end{array}$ & Representative Point of View \\
\hline B3 & "Our family income is limited. My son works in Guangzhou as a migrant laborer. Thus, \\
we cannot afford to donate."
\end{tabular}

Note: (1) Representative views are derived from interview records. (2) " $\mathrm{A}$ " indicates a positive response for payment, whereas " $B$ " indicates a negative response.

\subsection{Non-Use Value Assessment}

Non-use value as an intrinsic property of environmental resources, is often obtained from the product of respondents' mean WTP and the total number of local residents. The formula for calculating non-use value is as follows:

$$
E=X \times n \times Y
$$

where $E$ is the total number of non-use value, $X$ is the mean WTP for protecting Zengcheng's litchi heritage, $n$ is the total population in Zengcheng District, and $Y$ is the WTP rate. According to the foregoing analysis, the mean WTP was 62.5 CNY per year, and the WTP rate was $66.6 \%$. The total number of Zengcheng's population in 2017 was 119.83 million. From Equation (2), the non-use value for the Lingnan Litchi Cultivation System (Zengcheng) in 2018 was estimated at 49.9 million CNY.

In this study, the option, bequest, and existence values were listed for respondents to decompose the total number of the WTP. From statistics, the ratio of option, bequest, and existence values to the sum of residents' WTP was $40.3 \%, 27.4 \%$, and $32.3 \%$, respectively. Based on the different proportions of respondents' decomposition, the option, bequest, and existence values of the Lingnan Litchi Cultivation System (Zengcheng) in 2018 were worth 20.1, 13.7, and 16.1 million CNY, respectively, when the figures were accounted to one decimal place.

\section{Discussion}

First, the non-use values of IAHSs are usually underestimated. Based on the residents' WTP for protecting the IAHS under the current economic conditions, this study conducted an exploratory investigation on the non-use value of the Lingnan Litchi Cultivation System (Zengcheng). Evidently, this estimate can only be regarded as a rough approximation and may even underestimate the real non-use value. The main reasons are as follows:

(1) Compared with developed countries, the CVM bias should be more evident in underestimating resource value in developing countries [41].

(2) The decline of agricultural heritage resources can effectively lead to the growth of people's WTP. The impacts of modernization and industrialization often pose serious threats to traditional agricultural systems [14]. Zengcheng is located in the economic belt on the east of the Pearl River Delta. For a long time, the urbanization rate has continued to rise, whereas the planting area of crops has declined annually. People's cognition for agricultural heritage protection is inevitably enhanced because of the decline of agricultural resources, the growth of urbanization rate, the improvement of people's living standards, and other factors $[23,40]$.

(3) Although the interviewees are local residents, they may not have a comprehensive understanding of the Lingnan Litchi Cultivation System (Zengcheng), especially its value concerning litchi varieties, cultural relics, traditional knowledge, and ecosystem service functions. As a result, the respondents' WTP may be lower than its actual value.

(4) Including this research, most studies on the non-use value of IAHSs are conducted on the basis of the evaluation of local residents' WTP. Voluntary donation plays an increasingly important role in 
funding public goods [42]. IAHSs have a considerable influence, and some residents outside the local area must have a certain willingness to pay for their conservation [24,43].

Second, the attributes of IAHSs play an important role in WTP evaluation. As shown in Table 6, compared with other relevant studies in China, the mean WTP and positive payment rate of this study are at a medium normal level. IAHSs have many types. Thus, the individual characteristics of an IAHS can inevitably have certain impacts on the WTP of residents. The mean WTP and the positive payment rate of the Chongyi Hakka Terrace System, which is a heritage type of landscape, are the strongest of four cases. Tourism development in heritage sites can effectively enhance the value of agricultural heritage, and their multi-values can be achieved as soon as eco-tourism is developed in agricultural heritage sites $[44,45]$. The tourism value of terraced landscapes is strong, wherein the Hakka Terrace scenic spots received 0.4 million tourists in 2015 [46]. The cognition level of heritage value is a significant influencing factor. The residents in landscape heritage sites, who are affected by tourism publicity, should be inclined to pay for protecting heritage.

Table 6. Willingness to pay (WTP) comparison between the results of this study and other similar research findings in China.

\begin{tabular}{ccccc}
\hline Cases Study & Year & $\begin{array}{c}\text { Main Heritage } \\
\text { Content }\end{array}$ & $\begin{array}{c}\text { Mean WTP } \\
\text { (CNY/a) }\end{array}$ & $\begin{array}{c}\text { Positive Payment } \\
\text { Rate }\end{array}$ \\
\hline $\begin{array}{c}\text { Fuzhou Jasmine Planted and Tea } \\
\text { Cultural Systems, Fujian } \\
\text { (China-NIAHS and GIAHS) [23] }\end{array}$ & 2013 & $\begin{array}{c}\text { Jasmine farming; } \\
\text { Jasmine tea } \\
\text { processing }\end{array}$ & $\begin{array}{c}25.7 \text { (Rural); } \\
64.6 \text { (Urban) }\end{array}$ & $66.2 \%$ \\
\hline $\begin{array}{c}\text { Chongyi Hakka Terrace System, } \\
\text { Jiangxi (China-NIAHS and } \\
\text { GIAHS) [12] }\end{array}$ & 2015 & $\begin{array}{c}\text { Landscape of } \\
\text { terraces; rice } \\
\text { farming }\end{array}$ & 135.9 & $75.9 \%$ \\
\hline $\begin{array}{c}\text { Anxi Tieguanyin Tea Culture System, } \\
\text { Fujian (China-NIAHS) [47] }\end{array}$ & 2015 & $\begin{array}{c}\text { Tea tree farming; } \\
\text { tea processing }\end{array}$ & 27.5 & $63.3 \%$ \\
\hline Current study (China-NIAHS) & 2018 & $\begin{array}{c}\text { Litchi farming; } \\
\text { ancient trees }\end{array}$ & 62.5 & $66.6 \%$ \\
\hline
\end{tabular}

Third, local cultures should be considered a great concern. Agricultural culture (e.g., customs, religion, and festivals) is an important part of IAHSs [48]. Traditional landscapes and knowledge are always managed by small groups of farmers, pastoralists, and fishmen who are engaged in traditional practices related to farming; thus, the role of local cultures cannot be ignored in exploring the non-use value of IAHSs [49]. Zengcheng is home to many famous litchi cultivars (e.g., "Gualü", "Shangshuhuai", "Shuijingqiu", "Xuehuaizi", and "Zhumazi"), thus having gained the reputation of being the "Hometown of Litchi" since ancient times. The WTP for the litchi heritage system is relatively high because of its relationship, to a large extent, with the existence of large areas of litchi trees, especially ancient trees. Such an existence is an important tourism image of Zengcheng. Previous studies prove that the degree of "naturality" of a forest recreational setting seems to have a positive effect on the WTP as captured by the overall quality index, the percentage of old trees, and the presence of a nature reserve in the forest [25]. The enthusiasm of residents for heritage is an important influencing factor, whereas the landscape of litchi trees provides a key carrier for this enthusiasm in Zengcheng [12]. The traditional culture of worshiping ancestors is deeply rooted in the hearts of people. Most residents that were interviewed believe that the ancient litchi trees are precious wealth left by ancestors and should be protected carefully. Therefore, the impact of local cultures on the WTP of residents should not be ignored and is worth further research. 


\section{Conclusions}

Non-use value is an important part of the value of IAHSs, and if ignored, the objectives that must be protected cannot be fully recognized. Taking the China-NIAHS site the Lingnan Litchi Cultivation System (Zengcheng) as a case, this study conducted a survey on the WTP for protecting the IAHS. The non-use value was then assessed using the CVM. The following conclusions were drawn:

(1) The WTP rate of residents in the heritage site was $66.6 \%$, and the mean WTP was $62.5 \mathrm{CNY}$ per year. In 2018, the total non-use value of the Lingnan Litchi Cultivation System (Zengcheng) was 49.9 million CNY. The option, bequest, and existence values were estimated to be 20.1, 13.7, and 16.1 million CNY, respectively.

(2) The results of the logistic regression analysis showed that the variables of age, education level, financial burden, and heritage value cognition were significant factors of the WTP for protecting the litchi heritage. Meanwhile, a negative correlation was found between the WTP and age or financial burden. Moreover, $33.4 \%$ of respondents chose the non-payment option due to their low economic income or heavy financial burden.

Furthermore, this study confirms that the non-use value of IAHSs is usually underestimated. Compared with similar studies in China, the mean WTP and positive payment rate in this study are at a medium normal level. Resource attributes and regional cultures should have significant impacts on the composition and assessment of the non-use value of IAHSs. Exploring the non-use value of IAHSs can provide useful reference for perfecting compensatory mechanisms and formulating policies of heritage conservation. In the future, researchers should incorporate theories from other fields and conduct additional case studies to verify and compare the results of the non-use value of IAHSs. Further studies must prompt policymakers to generate the proper incentives to move from only a heritage babel to a real conservation initiative in IAHS sites [24].

Author Contributions: F.Z. designed the framework and provided direction for the research. F.Z. and M.H. wrote the manuscript. All authors have read and agreed to the published version of the manuscript.

Funding: This study was supported by the Major Program of National Social Science Foundation of China (No. 16ZDA123), the China Scholarship Council Program of Study Abroad for Young Scholars (No. 201907630012), and the Bidding Program of Agricultural and Rural Authority of Zengcheng District, Guangzhou City, China (No. skczx2018041).

Acknowledgments: The authors sincerely thank colleagues at the Zengcheng Agricultural and Rural Authority and all respondents for their generous support. Special thanks to Maohe Li, Meijing Liao, Zhanhui Zhang, Rui Nie, Miaomiao Jiang, Lingyu Pang, and others for their work on the survey.

Conflicts of Interest: The authors declare no conflict of interest.

\section{References}

1. Mitchell, N.J.; Barrett, B. Heritage Values and Agricultural Landscapes: Towards a New Synthesis. Landsc. Res. 2015, 40, 701-716. [CrossRef]

2. Ramakrishnan, P.S. Globally Important Ingenious Agricultural Heritage Systems (GIAHS): An Eco-Cultural Landscape Perspective; GIAHS Background Document; FAO: Rome, Italy, 2004.

3. Zhao, L.-J.; Xu, W.-S.; Sun, Y.-H.; Min, Q.-W.; He, L. On the conservation of China's Agricultural Heritage Systems. Chin. J. Eco-Agric. 2012, 20, 688-692. (In Chinese) [CrossRef]

4. Sousa, A.R.; Barandica, J.M.; Sanz-Cañada, J.; Rescia, A.J. Application of a dynamic model using agronomic and economic data to evaluate the sustainability of the olive grove landscape of Estepa (Andalusia, Spain). Landsc. Ecol. 2019, 34, 1547-1563. [CrossRef]

5. Sousa, A.R.; Parra-López, C.; Sayadi-Gmada, S.; Barandica, J.; Rescia, A. A multifunctional assessment of integrated and ecological farming in olive agroecosystems in southwestern Spain using the Analytic Hierarchy Process. Ecol. Econ. 2020, 173, 106658. [CrossRef]

6. Koohafkan, P.; Altieri, M.A. Globally Important Agricultural Heritage Systems: A Legacy for the Future; FAO: Rome, Italy, 2011. 
7. Loomis, J. Broadening the Concept and Measurement of Existence Value. Northeast. J. Agric. Resour. Econ. 1988, 17, 23-29. [CrossRef]

8. Koohafkan, P.; Altieri, M.A. Forgotten Agricultural Heritage: Reconnecting Food Systems and Sustainable Development; Earthscan Food and Agriculture Series; Routeledge: London, UK, 2016; pp. 55-56.

9. Bostedt, G.; Lundgren, T. Accounting for cultural heritage - A theoretical and empirical exploration with focus on Swedish reindeer husbandry. Ecol. Econ. 2010, 69, 651-657. [CrossRef]

10. Min, Q.; Zhang, B. Research Progress in the Conservation and Development of China-Nationally Important Agricultural Heritage Systems (China-NIAHS). Sustainability 2019, 12, 126. [CrossRef]

11. Min, Q.; Zhang, Y.; Jiao, W.; Sun, X. Responding to common questions on the conservation of agricultural heritage systems in China. J. Geogr. Sci. 2016, 26, 969-982. [CrossRef]

12. Hu, X.; Min, Q.; Lai, G.; Wu, Q.; Chen, T.; Pan, S. Regional differences in the willingness to pay for non-use value of agriculture heritage: Chongyi Hakka Terrace System in Jiangxi. Resour. Sci. 2017, 39, 737-746. (In Chinese)

13. Min, Q.; Zhang, Y. Comparison between Agri-cultural Heritage Systems and Agri-cultural Landscape. China Agric. Univ. J. Soc. Sci. Ed. 2016, 33, 119-126. (In Chinese)

14. Min, Q.; Sun, Y. The Concept, Characteristics and Conservation Requirements of Agro-cultural Heritage. Resour. Sci. 2009, 31, 914-918. (In Chinese)

15. Daugstad, K.; Rønningen, K.; Skar, B. Agriculture as an upholder of cultural heritage? Conceptualizations and value judgements-A Norwegian perspective in international context. J. Rural. Stud. 2006, 22, 67-81. [CrossRef]

16. Luo, S.; Sun, Q. The development of agricultural ecology and the responsibility of university mission: Interview with Professor Shiming Luo. China Agric. Univ. J. Soc. Sci. Ed. 2017, 34, 5-19. (In Chinese)

17. Krutilla, J.V. Conservation reconsidered. Am. Econ. Rev. 1967, 57, 777-786.

18. Carson, R.T. Contingent Valuation; North Holland: Amsterdam, The Netherlands, 1989; pp. 862-869.

19. Pearce, D.W.; Turner, R.K. Economics of Natural Resources and the Environment; Harvester Wheatsheaf: London, UK, 1990.

20. Liu, J.; Zhang, Y. Review of non-use value evaluation of tourism resource. Trop. Geogr. 2017, 37, $130-141$. (In Chinese) [CrossRef]

21. Liu, J.; Liu, N.; Zhang, Y.; Qu, Z.; Yu, J. Evaluation of the non-use value of beach tourism resources: A case study of Qingdao coastal scenic area, China. Ocean Coast. Manag. 2019, 168, 63-71. [CrossRef]

22. Berweck, S.; Koohafkan, P.; Cruz, M.J.R.D.; Qingwen, M.; Wenjun, J.; Yehong, S.; Moucheng, L. Conceptual Framework for Economic Evaluation of Globally Important Agricultural Heritage Systems (GIAHS): Case of Rice-Fish Co-Culture in China. J. Resour. Ecol. 2013, 4, 202-211. [CrossRef]

23. Lin, X.; Yan, Y.; Min, Q.; Wang, J.; Zheng, J.; Zhang, Y.; Wang, W. Evaluating the non-use value of agricultural heritage across Jasmine Planted and Tea Cultural Systems in Fuzhou. Resour. Sci. 2014, 36, 1089-1097. (In Chinese)

24. Barrena, J.; Nahuelhual, L.; Báez, A.; Schiappacasse, I.; Cerda, C. Valuing cultural ecosystem services: Agricultural heritage in Chiloé Island, Southern Chile. Ecosyst. Serv. 2014, 7, 66-75. [CrossRef]

25. Scarpa, R.; Hutchinson, W.G.; Chilton, S.M.; Buongiorno, J. Importance of forest attributes in the willingness to pay for recreation: A contingent valuation study of Irish forests. For. Policy Econ. 2000, 1, 315-329. [CrossRef]

26. Wang, Z.; Guo, L.; Zhang, J. Non-use value composition ratio and influencing factors in different attributes of resources based on cross-cases perspective. Resour. Sci. 2017, 39, 723-736. (In Chinese)

27. Mell, I.C.; Henneberry, J.; Hehl-Lange, S.; Keskin, B. Promoting urban greening: Valuing the development of green infrastructure investments in the urban core of Manchester, UK. Urban For. Urban Green. 2013, 12, 296-306. [CrossRef]

28. Sun, Y.; Min, Q.; Liu, M. Tourism resources utilization of different types of agricultural heritage systems. Resour. Sci. 2013, 35, 1526-1534. (In Chinese)

29. Li, J. Litchi Science; China Agriculture Press: Beijing, China, 2008; p. 3. (In Chinese)

30. Groff, G.W. The Lychee and Lungan; Orange Judd Company: New York, NY, USA, 1921; pp. $45-89$.

31. Zhao, F. From ignorance to successful introduction: Chinese lychee in western countries, 1570-1921. Agric. Hist. China 2019, 38, 26-36. (In Chinese) 
32. Chen, H.; Ou, L.; Li, J.; Su, Z.; Yang, S.; Wu, Z.; Hu, Z. Fruit scientific research in New China in the past 70 years: Litchi. J. Fruit. Sci. 2019, 36, 1399-1413. (In Chinese)

33. Popenoe, W. Manual of Tropical and Subtropical Fruits; The Macmillan Company: New York, NY, USA, 1920; p. 315.

34. Zengcheng Local Chronicle Compilation Committee. Zengcheng County Annals; Guangdong People's Publishing House: Guangzhou, China, 1995. (In Chinese)

35. Zhao, F.; Liao, M.; Zhang, J.; Huang, M.; Zhang, Z. Characteristics, value, and conservation of litchi heritage systems in China: A case study of the Lingnan Litchi Cultivation System (Zengcheng). Chin. J. Eco-Agric. 2020. (In Chinese) [CrossRef]

36. Noonan, D.S. Contingent Valuation and Cultural Resources: A Meta-Analytic Review of the Literature. J. Cult. Econ. 2003, 27, 159-176. [CrossRef]

37. Hansen, T.B. The Willingness-to-Pay for the Royal Theatre in Copenhagen as a Public Good. J. Cult. Econ. 1997, 21, 1-28. [CrossRef]

38. Jiao, Y.; Ao, C. Research development of contingent value method in ecological environments evaluation. J. Northeast. Agric. Univ. 2008, 5, 131-136. (In Chinese)

39. Loomis, J.; Lockwood, M.; DeLacy, T. Some Empirical Evidence on Embedding Effects in Contingent Valuation of Forest Protection. J. Environ. Econ. Manag. 1993, 25, 45-55. [CrossRef]

40. Ranjith, B.; Clem, T. Changing abundance of elephants and willingness to pay for their conservation. J. Environ. Manag. 2005, 76, 47-59.

41. Dong, X.; Zhang, J.; Liu, C.; Li, M.; Zhong, S. Bias analysis and reliability and validity test in Contingent Valuation Method: A case study of assessment of Jiuzhaigou's recreational value. Acta Geol. Sin. 2011, 66, 267-278. (In Chinese)

42. Sanz, J.Á.; Herrero, L.C.; Centeno, A.B. Contingent Valuation and Semiparametric Methods: A Case Study of the National Museum of Sculpture in Valladolid, Spain. J. Cult. Econ. 2003, 27, 241-257. [CrossRef]

43. Wang, Z.; Gong, Y.; Mao, X. Exploring the value of overseas biodiversity to Chinese netizens based on willingness to pay for the African elephants' protection. Sci. Total Environ. 2018, 637, 600-608. [CrossRef] [PubMed]

44. Tian, M.; Min, Q.; Hui, T.; Zheng, Y.; Lu, H.; Lun, F. Progress and Prospects in Tourism Research on Agricultural Heritage Sites. J. Resour. Ecol. 2014, 5, 381-389. [CrossRef]

45. Zhao, F.; Nie, R.; Zhang, J. Greenway Implementation Influence on Agricultural Heritage Sites (AHS): The Case of Liantang Village of Zengcheng District, Guangzhou City, China. Sustainability 2018, 10, 434. [CrossRef]

46. Miao, J.; Wang, Z.; Yang, W.; Yang, B.; Huang, G. Development status, problems and its countermeasures of Chongyi Hakka terrace ecosystem. Ecol. Sci. 2018, 37, 218-224. (In Chinese)

47. Ta, S. A Study on the Non-Use Value Evaluation and Protection Strategies to Agricultural Cultural Heritage of Tie Kuan Yin; Fujian Agriculture and Forestry University: Fuzhou, China, 2017. (In Chinese)

48. Zhang, Y.; Li, X.; Min, Q. How to balance the relationship between conservation of Important Agricultural Heritage Systems (IAHS) and socio-economic development? A theoretical framework of sustainable industrial integration development. J. Clean. Prod. 2018, 204, 553-563. [CrossRef]

49. Agnoletti, M.; Rotherham, I.D. Landscape and biocultural diversity. Biodivers. Conserv. 2015, 24, 3155-3165. [CrossRef]

(C) 2020 by the authors. Licensee MDPI, Basel, Switzerland. This article is an open access article distributed under the terms and conditions of the Creative Commons Attribution (CC BY) license (http://creativecommons.org/licenses/by/4.0/). 